\title{
Robust Position Tracking Control of an Electro-Hydraulic Actuator in the Presence of Friction and Internal Leakage
}

\author{
Zulfatman Has • Mohd Fua'ad Rahmat • Abdul Rashid Husain • Kashif Ishaque • \\ Rozaimi Ghazali • Mohamed Noh Ahmad • Yahaya Md Sam • Sahazati Md Rozali
}

Received: 27 June 2012 / Accepted: 15 November 2012 / Published online: 20 November 2013

(C) King Fahd University of Petroleum and Minerals 2013

\begin{abstract}
This paper proposes an improved robust position controller for the electro-hydraulic actuator system using the varying boundary layered sliding mode control scheme. The proposed scheme has the ability to improve the position tracking performance of the actuator in the presence of friction and internal leakage. The former is represented using the LuGre model while later is modelled as a turbulent flow. To evaluate the effectiveness of the proposed method, MATLAB simulations are carried out under friction and leakage effects. Its performance is compared with the conventional PID and fuzzy PID (FPID) methods. Finally, an experimental rig that comprises of a single-rod and double acting hydraulic cylinder is set up to validate the proposed idea. The software development is carried out in the DSpace 1104 environment using a TMS320F240 digital signal processor. The superiority of the proposed method over the PID and FPID in terms of tracking position is highlighted by simulation and experimental results.
\end{abstract}

Z. Has · M. F. Rahmat $(\bowtie) \cdot$ A. R. Husain · M. N. Ahmad .

Y. M. Sam

Department of Control and Mechatronic Engineering,

Faculty of Electrical Engineering, Universiti Teknologi Malaysia,

81310 Skudai, Johor, Malaysia

e-mail: fuaad@fke.utm.my

K. Ishaque

Karachi Institute of Economics and Technology,

Karachi 75190, Pakistan

R. Ghazali

Department of Mechatronic and Robotic Engineering,

Faculty of Electrical and Electronic Engineering,

Universiti Tun Hussein Onn, 96400 Batu Pahat, Johor, Malaysia

S. M. Rozali

Department of Control and Automation,

Faculty of Electrical Engineering, Universiti Teknikal Malaysia

Melaka, Hang Tuah Jaya, 76100 Durian Tunggal, Melaka, Malaysia
Keywords Hydraulic actuator · Position control . Sliding mode $\cdot$ Internal leakage $\cdot$ Friction

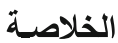

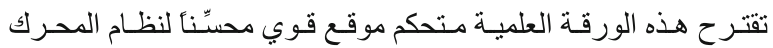

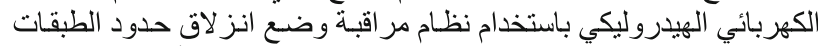

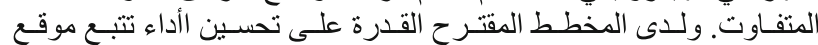

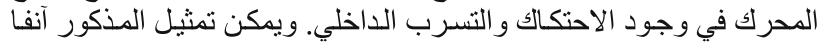

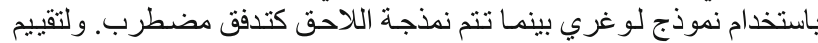

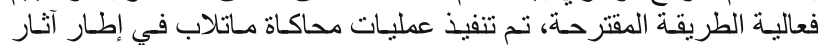

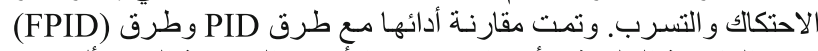

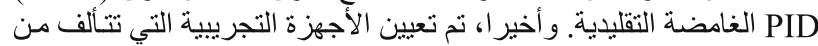

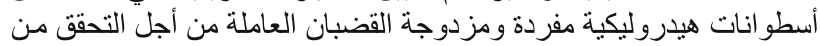

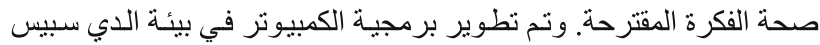

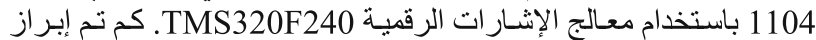

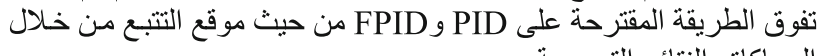

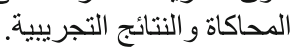

\section{List of Symbols}

$A_{1}, A_{2} \quad$ Cross-sectional area of the two chambers $\left(\mathrm{m}^{2}\right)$

a Nonlinear dynamics

$\hat{a} \quad$ Estimation of nonlinear dynamics

$a_{\mathrm{p}} \quad$ Piston acceleration $\left(\mathrm{m} / \mathrm{s}^{2}\right)$

$\dot{a}_{\mathrm{p}} \quad$ Piston jerk $\left(\mathrm{m} / \mathrm{s}^{3}\right)$

$b \quad$ Control gain

$\hat{b} \quad$ Estimation of control gain

$b_{\min } \quad$ Lower bound of control gain

$b_{\max } \quad$ Upper bound of control gain

$C_{\mathrm{d}} \quad$ Discharge coefficient

$C_{\mathrm{v} 1}, C_{\mathrm{v} 1} \quad$ Valve orifice coefficients

$d_{u} \quad$ External disturbance

$D \quad$ Maximum disturbance

$e \quad$ Error trajectory

$\dot{e} \quad$ Derivative of error 
E $\quad$ Error bounded

$F_{\mathrm{a}} \quad$ Hydraulic actuating force $(\mathrm{N})$

$F_{\mathrm{c}} \quad$ Coulomb friction $(\mathrm{N})$

$F_{\mathrm{f}} \quad$ Hydraulic friction force $(\mathrm{N})$

$\dot{F}_{\mathrm{f}} \quad$ Derivative of friction force

$F_{\mathrm{S}} \quad$ Stiction force (N)

$f_{\mathrm{d}} \quad$ Lumped uncertain nonlinearities

$\dot{f}_{\mathrm{d}} \quad$ Derivative of lumped uncertain nonlinearities

$I_{\max } \quad$ Max. current for servo valve

$k_{\mathrm{a}} \quad$ Servo valve gain $(\mathrm{m} / \mathrm{V})$

$K_{\mathrm{f} 1}, K_{\mathrm{f} 2} \quad$ Flow gain at control ports 1 and 2

$K_{1 \mathrm{R}}, K_{2 \mathrm{R}} \quad$ Flow gain at return ports 1 and 2

$K_{1 \mathrm{~S}}, K_{2 \mathrm{~S}} \quad$ Flow gain at supply ports 1 and 2

$k_{\mathrm{f} 1}, k_{\mathrm{f} 2} \quad$ Leakage coefficient at ports 1 and 2

$k_{1 \mathrm{R}}, k_{2 \mathrm{R}} \quad$ Leakage coefficient at return ports 1 and 2

$k_{1 \mathrm{~S}}, k_{2 \mathrm{~S}} \quad$ Leakage coefficient at supply ports 1 and 2

$k_{\mathrm{v}} \quad$ Viscous friction $(\mathrm{N} \mathrm{s} / \mathrm{m})$

$m \quad$ Total mass of piston and load $(\mathrm{kg})$

$\dot{p}_{l}, \dot{p}_{2} \quad$ Derivative of pressure in chambers 1 and $2(\mathrm{~Pa} / \mathrm{s})$

$p_{\mathrm{r}} \quad$ Return pressure $(\mathrm{Pa})$

$p_{\mathrm{s}} \quad$ Supply pressure $(\mathrm{Pa})$

$p_{1}, p_{2} \quad$ Pressure in chambers 1 and $2(\mathrm{~Pa})$

$Q \quad$ Discontinuous switching gain

$Q_{\mathrm{S} 1}, Q_{\mathrm{S} 2} \quad$ Internal leakage flow in control ports 1 and $2\left(\mathrm{~m}^{3} / \mathrm{s}\right)$

$Q_{1}, Q_{2} \quad$ Fluid flow in chambers 1 and $2\left(\mathrm{~m}^{3} / \mathrm{s}\right)$

$Q_{1 \mathrm{R}}, Q_{2 \mathrm{R}} \quad$ Return flow at return ports 1 and $2\left(\mathrm{~m}^{3} / \mathrm{s}\right)$

$Q_{1 \mathrm{~S}}, Q_{2 \mathrm{~S}} \quad$ Supply flow at supply ports 1 and $2\left(\mathrm{~m}^{3} / \mathrm{s}\right)$

$Q_{\max } \quad$ Maximum permissible flow ( $\left.1 / \mathrm{min}\right)$

$S \quad$ Sliding surface

$\dot{S} \quad$ Derivative of sliding surface

$u \quad$ Input signal to the servo valve $(\mathrm{V})$

$u_{\text {eq }} \quad$ Equivalent control signal $(\mathrm{V})$

$u_{\mathrm{sw}} \quad$ Switching control signal $(\mathrm{V})$

$V \quad$ Lyapunov function

$\dot{V} \quad$ Derivative of Lyapunov function

$v_{\mathrm{p}} \quad$ Piston velocity $(\mathrm{m} / \mathrm{s})$

$v_{\mathrm{s}} \quad$ Stribeck velocity $(\mathrm{m} / \mathrm{s})$

$V_{1}, V_{2} \quad$ Total actuator volume in chambers 1 and $2\left(\mathrm{~m}^{3}\right)$

$V_{i 1}, V_{i 2} \quad$ Initial volume in chambers 1 and $2\left(\mathrm{~m}^{3}\right)$

$w_{1}, w_{2} \quad$ Spool valve area gradients $\left(\mathrm{m}^{2}\right)$

$x_{\mathrm{d}} \quad$ Desired position (m)

$x_{\mathrm{p}} \quad$ Piston position (m)

$x_{\mathrm{v}} \quad$ Spool valve displacement $(\mathrm{m})$

$\dot{x}_{\mathrm{v}} \quad$ Spool valve velocity $(\mathrm{m} / \mathrm{s})$

$\ddot{x}_{\mathrm{v}} \quad$ Spool valve acceleration $\left(\mathrm{m} / \mathrm{s}^{2}\right)$

$x_{0} \quad$ Equivalent orifice opening $(\mathrm{m})$

$\dot{x}_{\mathrm{p}} \quad$ Piston velocity $(\mathrm{m} / \mathrm{s})$

$z \quad$ Average of bristle deflection

$\dot{z} \quad$ Derivative of average of bristle deflection

$\omega_{\mathrm{v}} \quad$ Servo valve natural frequency $(\mathrm{Hz})$ $\beta_{\mathrm{e}} \quad$ Effective bulk modulus (Pa)

$\zeta_{\mathrm{v}} \quad$ Servo valve damping ratio

$\tau_{\mathrm{v}} \quad$ Time constant (s)

$\phi \quad$ Thickness of boundary layer

$\phi_{a} \quad 1$ st level of boundary layer

$\phi_{b} \quad$ 2nd level of boundary layer

$\sigma_{0} \quad$ Bristles stiffness coefficient $(\mathrm{N} / \mathrm{m})$

$\sigma_{1} \quad$ Bristles damping coefficient $(\mathrm{N} \mathrm{s} / \mathrm{m})$

$\rho \quad$ Fluid mass density $\left(\mathrm{kg} / \mathrm{m}^{3}\right)$

$\varepsilon_{\mathrm{f}} \quad$ Switching threshold of the tracking error

\section{Introduction}

Electro-hydraulic actuator (EHA) system has become one of the most important actuators in modern applications such as in production assembly lines, robotics, aircrafts equipments and submarine operations due to its fast and smooth response characteristics and high power density. It has excellent capabilities of positioning that gives a significant impact to the above applications in position control issues. However, EHA system exhibits the highly nonlinear properties, such as servo valve flow pressure, control fluid volumes, stiffness and associated friction. The friction introduces several problems such as tracking errors, limit cycles and poor stick-slip motion into the system $[1,2]$. A prior identification of these issues is indispensable in designed system to obtain the effective positioning performance.

An additional problem in the EHA system exists due to the effect of internal leakage flow. Due to the presumption of perfect geometry of EHA system, this flow is sometimes assumed to be zero. However, experimental findings in EHA system have, however, indicated the existence of this important issue. This leakage flows between the body and spool valve at the small spool displacements and decreases rapidly with the valve stroke due to the large overlap between the spool lands and the valve body. Consequently, it affects the orifice flow through the valve, which in turn degrades the performance of control action and slows down the movement of actuators. The exact amount of internal leakage is very difficult to obtain. Therefore, the original total flow is uncertain but imperative too. Hence, zero approximation of flow cannot be used, as it makes the performance of the control system unsatisfactory in some cases [3]. Therefore, to resolve these uncertainties, an appropriate selection of robust control strategy is very crucial.

In an effort to address these issues, various control schemes are proposed. The simplest approach is to adopt the linear control techniques for controlling the position of EHA system [4-7]. However, due to the linearization of the system, some significant dynamic properties are lost such as the change of viscosity and the bulk modulus of the elasticity of hydraulic oil, fluid compressibility, servo valve flow- 
pressure, dead band, variations in supply pressure and control volumes, stiffness, leakage and friction. Therefore, a nonlinear control method is most appropriate for these EHA systems and accordingly proposed by numerous researchers. Amongst these, a nonlinear observer-based controlled system in [8] is designed to investigate the existence of static and dynamic friction. In another attempt, authors in [9] have proposed an adaptive controller to mitigate the friction effects. This is followed by the most common techniques in nonlinear controllers inspired by Lyapunov design theory, such as robust control [10-12], sliding mode control (SMC) [13-15] and Backstepping control [16]. Furthermore, a fuzzy logic controller as proposed in [17] as an alternative choice to previous ones. However, FLC requires a substantial computational power due to the complexity of the process. Because, it deals with fuzzification, rule base storage, inference mechanism and defuzzification operations. Larger set of rules yields more accurate control at the expense of longer computational time $[18,19]$. Therefore, it is essential to propose a simple computational method yet effective robust nonlinear control that can be used in EHA system.

In the class of robust control, SMC envisaged to be a reasonable choice for a specific class of nonlinear systems. It exhibits excellent performance in uncertainties and nonlinearities. It provides a systematic method to maintain the stability and satisfactory performance in spite of modelling imperfections [20,21]. An attractive advantage of the SMC is that it is computationally simple and robust to parameter variations. Pertaining to these advantages, SMC has been successfully used in hydraulic system [22-24] for the friction compensation. But, to the best of the author's knowledge, it has not been adopted for the system with the consideration of internal leakage effects. Hence, with the inclusion of this factor and friction, the design of such type of controller to compensate these effects though tend to be a challenging but indispensable.

Hence, this work proposes a robust SMC controller to track the position of the EHA system in the presence of friction and internal leakage. In contrast to conventional SMC where fixed boundaries are usually used, proposed work utilizes the varying boundary layers. The modified SMC offers a smooth control action with very small chattering regardless of the change in tracking error bounds that normally exist in fixed layered SMC. The mathematical model of the system is represented by integrating the friction and internal leakage models into the EHA system. The friction is modelled using the LuGre model while the internal leakage is represented by leakage level in common valve.

To verify the effectiveness of the proposed controller, it is compared with PID and fuzzy PID (FPID) controller. In addition, the work compares the effects of fixed and varying boundary layers with respect to tracking performance of EHA system. Simulation and experimental results are pre- sented and discussed that validate the superior performance of the proposed SMC. The rest of the paper is organized as follows. The next section describes the EHA modelling. The mathematical modelling of friction and internal leakage is explained in the Sect. 3. In Sect. 4, SMC scheme with varying boundary layer is presented while Sect. 5 describes the overview of the overall simulation and experimental setup. To validate the idea, the control algorithm is implemented in DSpace 1104 environment with a TMS320F240 digital signal processor. In Sect. 6, proposed SMC is compared with classical and fuzzy PIDs, respectively. Finally, the conclusion is made in Sect. 7.

\section{Modelling of EHA System}

The servo valve and hydraulic cylinder are the two important components of an EHA system. Basically, EHA is a double-acting hydraulic cylinder with single-rod or single ended piston. A single load is normally attached at the end of the piston without the inclusion of spring and damper [25]. The schematic diagram of a typical EHA system is shown in Fig. 1. In this figure, $p_{\mathrm{s}}$ is the hydraulic supply pressure and $p_{\mathrm{r}}$ is the return pressure. $x_{\mathrm{v}}$ is the spool valve displacement, $Q_{1}$ and $Q_{2}$ are the fluid flow from and to cylinder, and $p_{2}$ and $p_{1}$ are the fluid pressure in the upper and lower cylinder chambers of the actuator [26].

The complete mathematical model of the system is comprised of the hydraulic actuator dynamics that usually includes the load- and the servo-valve dynamics [25,27] that accordingly describes the characteristics and behaviours of the electro-hydraulic system.

The dynamic equations for the motion of the piston can be written as

$\dot{x}_{\mathrm{p}}=v_{\mathrm{p}}$
$\dot{v}_{\mathrm{p}}=a_{\mathrm{p}}$
$a_{\mathrm{p}}=\frac{F_{\mathrm{a}}-F_{\mathrm{f}}-f_{\mathrm{d}}}{m}$

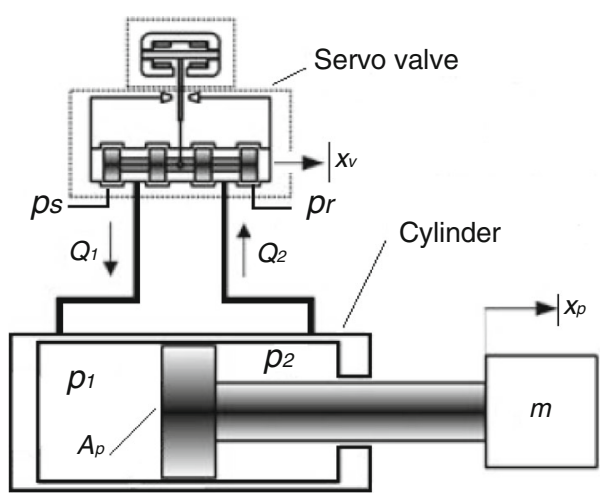

Fig. 1 Electro-hydraulic actuator 
where, $\dot{x}_{\mathrm{p}}$ and $v_{\mathrm{p}}$ are the piston velocities, $\dot{v}_{\mathrm{p}}$ and $a_{\mathrm{p}}$ are the piston accelerations, and $m$ is the total mass of the piston and load. From Eq. (2), there are two forces that need be derived from the dynamics of the system: the hydraulic actuating force, $F_{\mathrm{a}}$, and the hydraulic friction force, $F_{\mathrm{f}}$. While $f_{\mathrm{d}}$ is lumped uncertain nonlinearities due to external disturbance and other hard-to-model terms. The hydraulic actuating force, $F_{\mathrm{a}}$ can be represented as

$F_{\mathrm{a}}=A_{1} p_{1}-A_{2} p_{2}$

Hence,

$a_{\mathrm{p}}=\frac{\left(A_{1} p_{1}-A_{2} p_{2}\right)-F_{\mathrm{f}}-f_{\mathrm{d}}}{m}$

$A_{1}$ and $A_{2}$ are the cross-sectional area of the two chambers of the hydraulic cylinder, $p_{1}$ and $p_{2}$ are the chamber pressures of the cylinder.

The differential equation in (4) governs the dynamics of the EHA system. The total flow rate of each chamber can be obtained by taking the derivatives of pressure in the chamber and division of fluid capacitance. Since, internal leakage and compressibility factors are taken into consideration, the dynamics of cylinder fluid flow can be written as

$\frac{V_{1}}{\beta_{\mathrm{e}}} \dot{p}_{1}=-A_{1} v_{\mathrm{p}}-Q_{\mathrm{S} 1}+Q_{1}$

$\frac{V_{2}}{\beta_{\mathrm{e}}} \dot{p}_{2}=A_{2} v_{\mathrm{p}}+Q_{\mathrm{S} 2}-Q_{2}$

where, $V_{1}=V_{i 1}+x_{\mathrm{p}} A_{1}, V_{2}=V_{i 2}-x_{\mathrm{p}} A_{2}$

$V_{1}$ and $V_{2}$ are the total volume of the first and second chambers, $V_{i 1}$ and $V_{i 2}$ are the initial volume of the both chambers including the pipelines volume, $\beta_{\mathrm{e}}$ is the effective bulk modulus of hydraulic oil, $Q_{\mathrm{S} 1}$ and $Q_{\mathrm{S} 2}$ are the internal leakage in control ports 1 and 2, $Q_{1}$ and $Q_{2}$ are the supply and return flow rates of the forward and return chambers. It can be noted that external leakage is neglected in the cylinder due to the perfection of seal quality [27].

Using the equation of hydraulic fluid flow through an orifice in (5), the relationship between the flow rate of the chambers $Q_{1}, Q_{2}$, and spool valve displacement, $x_{\mathrm{v}}$ can now be written as

$$
\begin{aligned}
& Q_{1}=C_{\mathrm{v} 1} \sqrt{\Delta p_{1}}, \Delta p_{1}=\left\{\begin{array}{l}
p_{\mathrm{s}}-p_{1} \text { for } x_{\mathrm{v}} \geq 0 \\
p_{1} \text { for } x_{\mathrm{v}}<0
\end{array}\right. \\
& Q_{2}=C_{\mathrm{v} 2} \sqrt{\Delta p_{2}}, \Delta p_{2}=\left\{\begin{array}{l}
p_{2} \text { for } \mathrm{x}_{\mathrm{v}} \geq 0 \\
p_{\mathrm{s}}-p_{2} \text { for } \mathrm{x}_{\mathrm{v}}<0
\end{array}\right.
\end{aligned}
$$

Define function

$C_{\mathrm{v} 1}=C_{\mathrm{d}} w_{1} x_{\mathrm{v}} \sqrt{\frac{2}{\rho}}, \quad$ and $C_{\mathrm{v} 2}=C_{\mathrm{d}} w_{2} x_{\mathrm{v}} \sqrt{\frac{2}{\rho}}$

where, $C_{\mathrm{v} 1}$ and $C_{\mathrm{v} 2}$ are the valve orifice coefficients, $C_{\mathrm{d}}$ is the discharge coefficient, $w_{1}$ and $w_{2}$ are the spool valve area gradients, and $\rho$ is the oil density. Accordingly, from Eqs. (5)-(7), the hydraulic dynamics of the pressure of the cylinder can be shown as

$$
\begin{aligned}
& \dot{p}_{1}=\frac{\beta_{\mathrm{e}}}{V_{1}}\left(-A_{1} v_{\mathrm{P}}-Q_{\mathrm{S} 1}+C_{\mathrm{v} 1} \sqrt{\Delta p_{1}}\right) \\
& \dot{p}_{2}=\frac{\beta_{\mathrm{e}}}{V_{2}}\left(A_{2} v_{\mathrm{P}}+Q_{\mathrm{S} 2}-C_{\mathrm{v} 2} \sqrt{\Delta p_{2}}\right)
\end{aligned}
$$

The dynamic equation for the spool displacement of the servo valve, $x_{\mathrm{v}}$ is related to the control input $u$. The corresponding relation can be simplified by a first-order system is given as

$\dot{x}_{\mathrm{v}}=\frac{1}{\tau_{\mathrm{v}}}\left(-x_{\mathrm{v}}+k_{\mathrm{a}} u\right)$

where, $k_{\mathrm{a}}$ is the servo valve gain, and $\tau_{\mathrm{v}}$ is the time constant. Due to the use of a high-response servo valve, it is assumed that the control applied to the spool valve is directly proportional to the spool position [23]. Thus, the spool valve displacement is simplified as

$x_{\mathrm{v}}=k_{\mathrm{a}} u$

From Eqs. (1)-(10), if the state variables of the system model are selected as $x=\left[x_{1}, x_{2}, x_{3}\right]^{\mathrm{T}} \equiv\left[x_{\mathrm{p}}, v_{\mathrm{p}}, a_{\mathrm{p}}\right]^{\mathrm{T}}$. Then, the state equations of a third order model of a servo hydraulic actuator system can be obtained by neglecting the valve dynamic in (9) and replaced by (10), which follows

$$
\begin{aligned}
& \dot{x}_{1}=x_{2} \\
& \dot{x}_{2}=x_{3} \\
& \dot{x}_{3}=\dot{a}_{\mathrm{p}}=\frac{1}{m}\left[\left(A_{1} \dot{p}_{1}-A_{2} \dot{p}_{2}\right)-\dot{F}_{\mathrm{f}}-\dot{f}_{\mathrm{d}}\right]
\end{aligned}
$$

Substituting Eqs. (7), (8) and (10) into (11), we obtain

$$
\begin{aligned}
\dot{a}_{\mathrm{p}}= & \frac{1}{m}\left[\beta_{\mathrm{e}}\left(-\frac{A_{1}^{2}}{V_{1}}-\frac{A_{2}^{2}}{V_{2}}-\frac{A_{1} Q_{\mathrm{S} 1}}{V_{1} x_{2}}-\frac{A_{2} Q_{\mathrm{S} 2}}{V_{2} x_{2}}\right) x_{2}\right. \\
& +\beta_{\mathrm{e}} C_{\mathrm{d}} k_{\mathrm{a}} \sqrt{\frac{2}{\rho}}\left(\frac{A_{1} w_{1}}{V_{1}} \sqrt{\Delta p_{1}}+\frac{A_{2} w_{2}}{V_{2}} \sqrt{\Delta p_{2}}\right) u \\
& \left.-\dot{F}_{\mathrm{f}}-\dot{f}_{\mathrm{d}}\right]
\end{aligned}
$$

where, $a=-\frac{\beta_{\mathrm{e}}}{m}\left(\frac{A_{1}^{2}}{V_{1}}+\frac{A_{2}^{2}}{V_{2}}+\frac{A_{1} Q_{\mathrm{S} 1}}{V_{1} x_{2}}+\frac{A_{2} Q_{\mathrm{S} 2}}{V_{2} x_{2}}\right) x_{2}, b=$ $\frac{\beta_{\mathrm{e}} C_{\mathrm{d}} k_{\mathrm{a}} \sqrt{2 / \rho}}{m}\left(\frac{A_{1} w_{1}}{V_{1}} \sqrt{\Delta p_{1}}+\frac{A_{2} w_{2}}{V_{2}} \sqrt{\Delta p_{2}}\right)$,

$d_{u}=-\frac{1}{m}\left(\dot{F}_{\mathrm{f}}+\dot{f}_{\mathrm{d}}\right)$

Derivative of friction and lumped uncertain nonlinearities are taken into account as disturbances. Hence, from Eq. (12), the piston motion is obtained as single-input single-output nonlinear systems

$\dot{x}_{3}=a(x)+b(x) u+d_{u}$ 


\section{Friction and Internal Leakage Model}

The complete explanations of the terms friction, $F_{\mathrm{f}}$ and the internal leakage, $Q_{\mathrm{s}}$ introduced in Eqs. (4) and (5) are presented below, respectively.

\subsection{Friction Model}

Friction is a complex and a natural phenomenon. It occurs at the physical interface with a tangential reaction force between the two surfaces in contact [2]. It results tracking errors, limit cycle oscillation and undesirable stick-slip motion [1]. Friction always appears in hydraulic systems especially in cylinder rod and load environment. In this work, the existence of the friction is taken into consideration and a suitable model is selected to represent its behaviours.

Friction is commonly modelled as a discontinuous static mapping between the velocity and the friction force. The frictional force depends on the velocity's sign which is restricted to Coulomb and viscous friction. However, a static model cannot fully explain several behaviours such as stick-slip motion, pre-sliding displacement and friction lag. These properties are dynamic in nature; hence friction does not have an instantaneous response to a change of the velocity. To accommodate all these properties in static and dynamic friction together, friction force is modelled using LuGre friction model [14]. Since the model has capability to capture most of the friction behaviours, the model can be chosen to represent the friction function in differential equation of the EHA system as stated in (4).

Velocity-friction graph of the model that represents the friction characteristics for both static and dynamic frictions in the EHA system is shown in Fig. 2. The friction characteristics are generated during two cycles of oscillation. Relationship between velocity and friction is characterised from its hysteretic effects [28]. It can be seen that the oscilla-

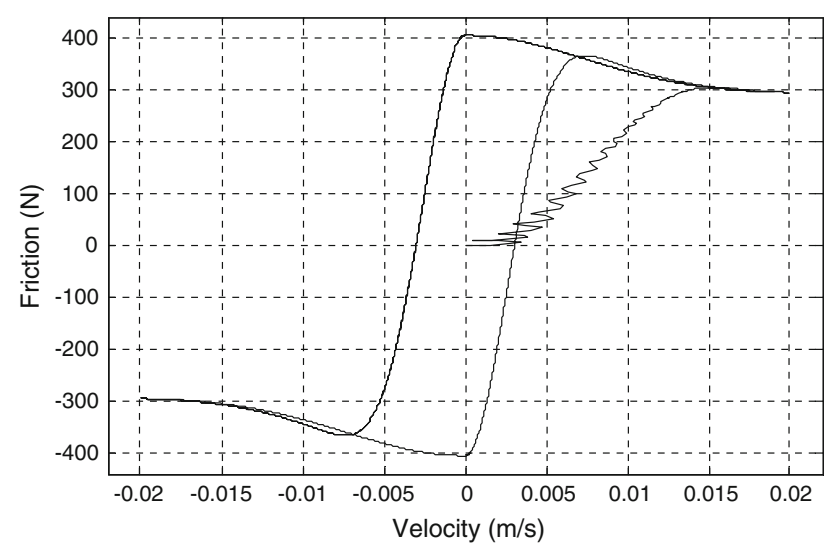

Fig. 2 LuGre friction-velocity description tion results a wide hysteretic effects around the zero relative velocity (pre-sliding motion area).

Mathematically, the LuGre friction model can be given as

$$
\begin{aligned}
& F_{\mathrm{f}}=\sigma_{0} z+\sigma_{1} \dot{z}+\sigma_{2} v_{\mathrm{p}}, \\
& \dot{z}=v_{\mathrm{p}}-\frac{\left|v_{\mathrm{p}}\right|}{g\left(v_{\mathrm{p}}\right)} z
\end{aligned}
$$

The friction internal state $z$ is described as deflections of the average bristle between each pair of the contact surface. The bristles will deflect the springs for small displacement. The bristles start to slip, if the deflection is sufficiently large. For a steady state motion, the average bristle deflection is determined by the velocity [2]. Friction force parameters $\sigma_{0}$, $\sigma_{1}$ and $\sigma_{2}$, respectively, are interpreted as the stiffness of the bristle between two contact surfaces, bristles damping coefficient and viscous friction coefficient. Different friction effects are described by a nonlinear function, $g\left(v_{\mathrm{p}}\right)$ and can be parameterized to characterise the Stribeck effect:

$g\left(v_{\mathrm{p}}\right)=\frac{1}{\sigma_{0}}\left(F_{\mathrm{c}}+\left(F_{\mathrm{s}}-F_{\mathrm{c}}\right) \mathrm{e}^{-\left(v_{\mathrm{p}} / v_{\mathrm{s}}\right)^{2}}\right)$,

where, $F_{\mathrm{c}}, F_{\mathrm{S}}$ and $v_{\mathrm{s}}$ are the Coulomb friction, viscous friction and Stribeck velocity, respectively. Thus, the complete friction model is represented by four static parameters and two dynamic parameters, stiffness coefficient and damping coefficient.

\subsection{Internal Leakage Model}

Internal leakage commonly flows between a servo valve and valve body. In an ideal servo valve, the leakage flows are zero, because it has a perfect geometry. In practice, the maximum leakage flow occurs at neutral spool position and is only a few percent of the rated flow rate. The leakage flow decreases rapidly with the valve stroke because of the large overlap between the spool lands and the valve body. In this paper, a nonlinear servo valve model is developed which accurately captures the leakage behaviour of the servo valve over for the whole ranges of spool movement. The leakage behaviour is modelled with a smooth transition from internal leakage to orifice flow based on asymmetric valve configuration. The flow area is inversely proportional to the overlap between the spool lands and the servo valve orifices [3].

Generally, a servo valve configuration consists of two control ports whose variable orifices regulate the flow rates, as shown in Fig. 3. The flow rates through the control ports, the supply and return ports of the servo valve are expressed as below

$$
\begin{aligned}
& Q_{1}=Q_{1 \mathrm{~S}}-Q_{1 \mathrm{R}} \text { and } Q_{2}=Q_{2 \mathrm{~S}}-Q_{2 \mathrm{R}} \\
& Q_{\mathrm{s}}=Q_{1 \mathrm{~S}}+Q_{2 \mathrm{~S}} \text { and } Q_{\mathrm{R}}=Q_{1 \mathrm{R}}+Q_{2 \mathrm{R}}
\end{aligned}
$$




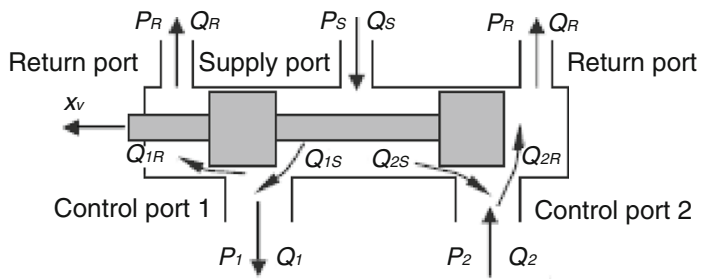

Fig. 3 Servo valve configuration

The flow rate at the supply and the return side of the port 1 is given by the orifice equation:

$Q_{1 \mathrm{~S}}=K_{1 \mathrm{~S}} \sqrt{\left(p_{\mathrm{s}}-p_{1}\right)}\left(x_{0}+x_{\mathrm{v}}\right)\left(x_{\mathrm{v}} \leq 0\right)$,

$Q_{1 \mathrm{R}}=K_{1 \mathrm{R}} \sqrt{\left(p_{1}-p_{\mathrm{r}}\right)} x_{0}^{2}\left(x_{0}+k_{1 \mathrm{R}} x_{\mathrm{v}}\right)^{-1}\left(x_{\mathrm{v}} \geq 0\right)$,

where, the parameter $x_{0}$ accounts for the leakage flow rate at null $\left(x_{\mathrm{v}}=0\right)$. Once, $x_{0}$ is equivalent to the spool displacement, the amount of flow from nonleaking servo valves and the leakage flow rate in a leaking servo valve will be same with a centred spool [3]. It can be also noted that the leakage flow rate is inversely proportional to spool displacement, since in larger valve opening the leakage resistance is increased.

From Eqs. (18)-(21), the following nonlinear relationships for control port 1 and port 2 can be obtained as

$$
\begin{aligned}
& Q_{1 \mathrm{~S}}=K_{1 \mathrm{~S}} \sqrt{\left(p_{\mathrm{s}}-p_{1}\right)}\left\{\begin{array}{l}
\left(x_{0}+x_{\mathrm{v}}\right),\left(x_{\mathrm{v}} \geq 0\right) \\
x_{0}^{2}\left(x_{0}-k_{1 \mathrm{~S}} x_{\mathrm{v}}\right)^{-1},\left(x_{\mathrm{v}}<0\right)
\end{array}\right. \\
& Q_{1 \mathrm{R}}=K_{1 \mathrm{R}} \sqrt{\left(p_{1}-p_{\mathrm{r}}\right)}\left\{\begin{array}{l}
x_{0}^{2}\left(x_{0}+k_{1 \mathrm{R}} x_{\mathrm{v}}\right)^{-1},\left(x_{\mathrm{v}} \geq 0\right) \\
\left(x_{0}-x_{\mathrm{v}}\right),\left(x_{\mathrm{v}}<0\right)
\end{array}\right. \\
& Q_{2 \mathrm{~S}}=K_{2 \mathrm{~S}} \sqrt{\left(p_{\mathrm{s}}-p_{2}\right)}\left\{\begin{array}{l}
x_{0}^{2}\left(x_{0}+k_{2 \mathrm{~S}} x_{\mathrm{v}}\right)^{-1},\left(x_{\mathrm{v}} \geq 0\right) \\
\left(x_{0}-x_{\mathrm{v}}\right),\left(x_{\mathrm{v}}<0\right)
\end{array}\right. \\
& Q_{2 \mathrm{R}}=K_{2 \mathrm{R}} \sqrt{\left(p_{2}-p_{\mathrm{r}}\right)}\left\{\begin{array}{l}
\left(x_{0}+x_{\mathrm{v}}\right),\left(x_{\mathrm{v}} \geq 0\right) \\
x_{0}^{2}\left(x_{0}-k_{2 \mathrm{R}} x_{\mathrm{V}}\right)^{-1},\left(x_{\mathrm{V}}<0\right)
\end{array}\right.
\end{aligned}
$$

With the assumption of symmetrical servo valve with matched control ports 1 and 2, the relationship between the leakages constants can be given as

$$
\begin{aligned}
K_{\mathrm{f} 1} & =K_{1 \mathrm{~S}}=K_{1 \mathrm{R}}, \text { and } \quad K_{\mathrm{f} 2}=K_{2 \mathrm{~S}}=K_{2 \mathrm{R}} \\
k_{\mathrm{f} 1} & =k_{1 \mathrm{~S}}=k_{1 \mathrm{R}}, \text { and } \quad k_{\mathrm{f} 2}=k_{2 \mathrm{~S}}=k_{2 \mathrm{R}}
\end{aligned}
$$

It was suggested in [17], the total supply flows in control ports 1 and 2, $Q_{\mathrm{S} 1}$ and $Q_{\mathrm{S} 2}$ represent the internal leakage flows since the control ports are blocked for an internal leakage test. The internal leakage flows can be expressed as

$$
Q_{\mathrm{S} 1}=K_{\mathrm{f} 1} \sqrt{\left(p_{\mathrm{S}}-p_{\mathrm{r}}\right)}\left(x_{0}+\left|x_{\mathrm{v}}\right|\right)\left(1 /\left(1+f_{1}\left(x_{\mathrm{v}}\right)\right)^{-1 / 2}\right.
$$

$$
\begin{aligned}
& Q_{\mathrm{S} 2}=K_{\mathrm{f} 2} \sqrt{\left(p_{\mathrm{s}}-p_{\mathrm{r}}\right)}\left(x_{0}+\left|x_{\mathrm{v}}\right|\right)\left(1 /\left(1+f_{2}\left(x_{\mathrm{v}}\right)\right)^{-1 / 2}\right. \\
& f_{1}\left(x_{\mathrm{v}}\right)=\left(1+\frac{\left|x_{\mathrm{v}}\right|}{x_{0}}\right)^{2}\left(1+k_{\mathrm{f} 1} \frac{\left|x_{\mathrm{v}}\right|}{x_{0}}\right), \text { and } \\
& f_{2}\left(x_{\mathrm{v}}=\left(1+\frac{\left|x_{\mathrm{v}}\right|}{x_{0}}\right)^{2}\left(1+k_{\mathrm{f} 2} \frac{\left|x_{\mathrm{v}}\right|}{x_{0}}\right)\right.
\end{aligned}
$$

which are valid for $x_{\mathrm{v}} \geq 0$, and $x_{\mathrm{v}}<0$

For any type of servo valve, available manufacturer data ( $Q_{\max }$ and $I_{\max }$ ) can be used to determine the servo valve leakage parameters such as $K_{f i}, k_{f i}$ and $x_{0}$ (for $i=1,2$ ) [3]. The servo valve leakage flow can be tested using several levels of orifice opening, $x_{0}$ from no leak to large leak $[1,2$, 17].

\section{Sliding Mode Control in Positioning of EHA System}

Before proceeding to proposed controller design, the following assumptions are made for a nonlinear system expressed in control canonical form in (14).

$|a(x)-\hat{a}(x)|=\Delta a(x) \leq E(x)$

$d_{u}<D$

It can be noted that the nonlinear dynamics of $a(x)$ is not known in prior. The nonlinear dynamics of $a(x)$ consist of variation of viscosity and volume of hydraulic oil changes with temperature, the change of fluid compressibility and uncertain total control volume caused by the internal leakage. Hence, it is estimated and referred as $\hat{a}(x)$ with errors bounded by a positive known function $E(x)$. The function $E(x)$ is made by the assumption that the parameters variation caused by the above behaviours will not be more than $50 \%$ of the nominal value of $a(x)$. Such that

$0<|E(x)| \leq 0.5$

In the same manner, the control gain $b(x)$ is also not known, because parameters $\beta_{\mathrm{e}}, C_{\mathrm{d}}, w$ and $\rho$ are varying parameters under different operating conditions. Thus, uncertainty is accordingly bounded to ensure that control gain do not cause control failure or reversal. This is given by following inequality

$0<b_{\min }(x) \leq b(x) \leq b_{\max }(x)$

where, $b_{\min }(x)$ and $b_{\max }(x)$ are the time-varying upper and lower bounds of $b(x)$, respectively. $\hat{a}(x)$ and $\hat{b}(x)$ correspond to the nominal parameters of the system, factor $d_{u}$ is the disturbance that represents derivative of friction and lumped uncertain nonlinearities, and $D$ is the maximum disturbance. In the dynamics, the control input is multiplied by the control gain while the geometric mean of the upper and lower bounds of the gain are taken as an estimation of $b(x)$, such that 
$\hat{b}(x)=\left(b_{\min }(x) b_{\max }(x)\right)^{1 / 2}$

\subsection{Proposed Control Law}

The designing of proposed SMC for position tracking control of the EHA system consists of selecting an equilibrium manifold or sliding surface, $S(x)$ to prescribe the desired dynamic characteristic of the controlled system, and designing a control law to drive the system to the sliding mode $S(x)=0$ and to maintain it there all the time [20].

The objective of the control design is to achieve a continuous sliding control, $u$, such that the output of the system tracks the desired input as closely as possible. At given desired position trajectory, $x_{\mathrm{d}}$, the control objective is to design a bounded control input, $u$. Hence the output position, $x_{\mathrm{p}}$, tracks as closely as possible to the desired position trajectory, $x_{\mathrm{d}}$, despite various model uncertainties. In designing a desired trajectory, the state error of the system is defined as

$$
\begin{aligned}
e_{i} & =x_{i}-x_{i d}, \text { where } i=1 \text { to } 3, \text { and } x=\left[x_{1}, x_{2}, x_{3}\right]^{\mathrm{T}} \\
& \equiv\left[x_{\mathrm{p}}, v_{\mathrm{p}}, a_{\mathrm{p}}\right]^{\mathrm{T}}
\end{aligned}
$$

To achieve the states of the system to track the desired trajectories at the same time, the function of sliding surface is defined as follows [14]

$S(e, t)=\left(\frac{\mathrm{d}}{\mathrm{d} t}+\lambda\right)^{2} e_{1}=\lambda^{2} e_{1}+2 \lambda e_{2}+e_{3}$

where $e$ is tracking error, defined as in (34)

$$
\begin{aligned}
& e_{1}=x_{1}(t)-x_{1 \mathrm{~d}}(t) \\
& e_{2}=x_{2}(t)-x_{2 \mathrm{~d}}(t) \\
& e_{3}=x_{3}(t)-x_{3 \mathrm{~d}}(t)
\end{aligned}
$$

$\lambda$ is a strictly positive constant to be specified according to the desired dynamics of the closed-loop system. The desired dynamic response for the system is given as $S=0$. If $S$ is forced to zero, the desired dynamics is attained and consequently, the tracking error will converge to zero.

To obtain the equivalent control, the derivative of the Eq. (35) gives

$$
\begin{aligned}
& \dot{S}=\lambda^{2} \dot{e}_{1}+2 \lambda \dot{e}_{2}+\dot{e}_{3} \\
& \dot{S}=\lambda^{2} \dot{e}_{1}+2 \lambda \dot{e}_{2}+\dot{x}_{3}-\dot{x}_{3 \mathrm{~d}}
\end{aligned}
$$

Substituting $\dot{x}_{3}$ from Eq. (14) gives

$$
\dot{S}=\lambda^{2} \dot{e}_{1}+2 \lambda \dot{e}_{2}+\hat{a}+\hat{b} u-\dot{x}_{3 \mathrm{~d}}
$$

The proposed control law of the SMC in this work is given as

$u=u_{\mathrm{eq}}+u_{\mathrm{sw}}$

where, $u_{\mathrm{eq}}$ and $u_{\mathrm{sw}}$ are the equivalent control signal and switching control, respectively. The signal of the equivalent control, $u_{\text {eq }}$, is obtained by formulating the derivative of sliding surface $\dot{S}=0$

$u_{\mathrm{eq}}=\hat{b}^{-1}(-\hat{a}-\hat{q})$

where, $\hat{q}=\lambda^{2} \dot{e}_{1}+2 \lambda \dot{e}_{2}-\dot{x}_{3 \mathrm{~d}}$

Another control signal is the switching control signal, $u_{\mathrm{sw}}$. It is designed to consider the uncertainties in the nonlinear dynamic $a$, to force all the trajectories states towards the sliding surface $S$ and to maintain them on the sliding surface. Switching control guarantees that the state is reached to the sliding mode regardless of existing uncertainties and disturbances. A common choice of switching control can be adopted as

$u_{\mathrm{sw}}=-\hat{b}^{-1} Q \operatorname{sgn}(S)$

Since the controller is designed to achieve a better tracking accuracy in positioning, a smaller boundary layer is usually required. Hence, an optimal balance between the position error and the level of control chattering can be accomplished by adjusting the thickness of the boundary layer $\phi>0$ and accordingly, it can be given as

$u_{\mathrm{sw}}=-\hat{b}^{-1} Q \operatorname{sat}(S / \phi)$

\subsection{Stability}

By choosing the Lypunov function candidate $V=0.5 \mathrm{~S}$ $(e, t)^{2}$, a reaching condition becomes

$\dot{V}=0.5 \frac{\mathrm{d}}{\mathrm{d} t} S^{2}(e, t)=S(e, t) \dot{S}(e, t) \leq-\eta|S(e, t)|$

where, $\eta$ must be a strictly positive design parameter. Substituting $\dot{S}$ from Eqs. (35) and (38) and using (43) gives

$$
\begin{aligned}
Q|S| \geq & S\left[\hat{b} b^{-1} a-\hat{a}+\hat{q}\left(\hat{b} b^{-1}-1\right)+\hat{b} b^{-1} D\right] \\
& +\eta \hat{b} b^{-1}|S|
\end{aligned}
$$

To meet the above condition, the discontinuous gain, $Q$ in (42) is determined as

$Q \geq \beta(E+\eta)+(\beta-1)|\hat{a}+\hat{q}|+D$

where, $\left|d_{u}\right|<D,|a-\hat{a}| \leq E, \hat{b} b^{-1} \geq \beta$ and gain margin, $\beta$, is introduced as

$\beta=\sqrt{b_{\max } / b_{\min }} \geq 1$,

\subsection{Varying Boundary Layers}

In SMC, the use of a boundary layer has been a common technique to reduce chattering of the control signal around the sliding surface. A continuous function interpolates the discontinuous switching function inside the boundary layer to avoid discontinuity of the control signals. Normally, the width of the boundary layer is constant, and the larger the 
boundary layer width, the smoother the control signal. For better tracking accuracy and a smoother control input, a smaller width of boundary layer is desirable. However, the error trajectory changes due to nonlinearities and uncertainties in the EHA system. Subsequently, the width of the boundary layer should also be changed to obtain an optimum tracking accuracy and smooth control input. Therefore, varying width of the boundary layers are proposed as

$\phi=\phi_{a} \chi(e)+\phi_{b}(1-\chi(e))$

Hence, the modified switching control of (42) can be rewritten as

$u_{\mathrm{sw}}=-\hat{g}^{-1} Q$ sat $\left(\frac{S}{\phi_{a} \chi(e)+\phi_{b}(1-\chi(e))}\right)$

where, $\phi_{a}$ and $\phi_{b}$ are different level boundary layers, with $0<\phi_{b}<\phi_{a}$. The logic for the boundary in the tracking error bounds defined as

$\chi(e)=1$ for $|e|>\varepsilon_{\mathrm{f}}$, and $\chi(e)=0$ for $|e| \leq \varepsilon_{\mathrm{f}}$

$\varepsilon_{\mathrm{f}}$ is positive constant which is used to declare the switching threshold of the tracking error. The initial state will be attached to the boundary layer of sliding surface, if the initial state is outside the boundary layer, $|S| \geq \phi_{a}$. The boundary layer changes from $\phi_{a}$ to $\phi_{b}$, if the absolute value of the trajectory error, $|\mathrm{e}|$, smaller than $\varepsilon_{\mathrm{f}}$. It results a significant improvement for the tracking accuracy and the chattering.

Conditions and widths of $\phi_{a}$ and $\phi_{b}$ of the boundary layer in the tracking error bounds area need to be defined clearly. The boundary layer, $\phi$ is obtained by trial-and-error approach. Its value is selected once a visible chattering in the control input signal occurs. Accordingly, the absolute value of $\phi$ is set to $\phi_{a}$. While, width of $\phi_{b}$ is set smaller than $\phi_{a}$ (in this proposed work it is around $1 / 5$ of $\phi_{a}$ ), which is a small enough to ensure no chattering in the control signal.

The existence of varying boundary layers in Eq. (48) for chattering reduction in the control signal around the sliding surface does not affect the stability analysis of the proposed controller. Equations (43)-(45) express that the stability is guaranteed by switching gain $Q$. It concludes that stability proof for the controller with varying boundary layers still remain the same as in the invariant boundary. Hence, the stability proof for the varying boundary does not need to be proofed.

\section{Simulation and Experimental Setup}

The tracking performance of the controller design is evaluated through several tests. The EHA system parameters are taken from the manufacturer datasheet of an existing EHA system. It is composed of a single-rod and double acting hydraulic cylinder and driven by a direct servo valve Bosch Rexroth 4WREE6, $40 \mathrm{lpm}$ flow rate at $70 \mathrm{bar}$. The dimensions of the hydraulic cylinder are 60/30/300 mm. Piston displacement is measured using $300-\mathrm{mm}$ draw wire sensor. Actual position of the spool valve is computed using LVDT sensor. A pair of 100 bar pressure transducers is attached to measure the pressure into and out of the cylinder. The control and associated acquisition data are implemented using dSPACE DS1104 card. Original position of the piston is set in the middle of the cylinder. Figure 4 depicts the complete test bed of the EHA system.

First, validation of the proposed controller is evaluated using simulations. Simulation helps to finely tune the controller. After the tuning process, the proposed controller is tested practically in the real system to validate its perfor-

Fig. 4 EHA system test bed

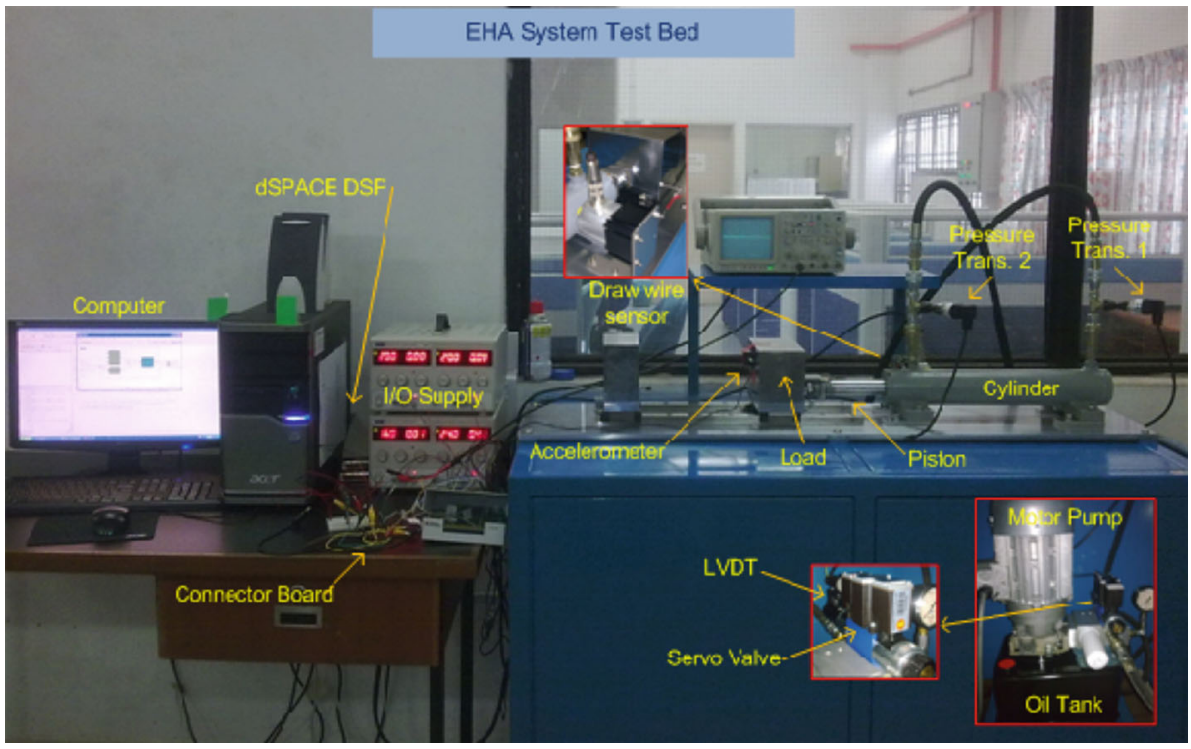


mance. In both simulation and experiment, sensitivity and performance of the proposed controller are compared to FPID and PID controllers. The difference in tuning method of the controllers is not necessary. Since the comparison is used only to highlight and to give a benchmark that the proposed controller is more capable to the others in compensating the friction and internal leakage. The main intention of this work is to observe capability of the proposed controller with varying boundary layers to reduce chattering and improve the tracking performance.

Table 1 shows the parameters of friction and internal leakage that are used in the proposed work. The control parameters for the SMC and PID controller are shown in Table 2. The PID controller parameters in Table 2 are optimized using the well-known Ziegler-Nichols method [29]. In FPID con-

Table 1 Parameters of the EHA system

Cylinder parameters

$\begin{array}{lll}p_{\mathrm{s}} & \text { Supply pressure }(\mathrm{Pa}) & 7 \times 10^{6} \\ V_{i 1} & \text { Initial volume in chamber } 1\left(\mathrm{~m}^{3}\right) & 0.602 \times 10^{-3} \\ V_{i 2} & \text { Initial volume in chamber } 2\left(\mathrm{~m}^{3}\right) & 0.496 \times 10^{-3} \\ A_{1} & \text { Actuator ram area in chamber } 1\left(\mathrm{~m}^{2}\right) & 2.826 \times 10^{-3} \\ A_{2} & \text { Actuator ram area in chamber } 2\left(\mathrm{~m}^{2}\right) & 2.120 \times 10^{-3} \\ x_{L} & \text { Total stroke of piston }(\mathrm{m}) & 0.3 \\ m & \text { Total mass of piston and load }(\mathrm{kg}) & 20 \\ \beta_{\mathrm{e}} & \text { Effective bulk modulus }(\mathrm{Pa}) & 1 \times 10^{9} \\ \rho & \text { Fluid mass density }\left(\mathrm{kg} / \mathrm{m}^{2}\right) & 850\end{array}$

Servo valve parameters

$\begin{array}{lll}C_{\mathrm{d}} & \text { Discharge coefficient } & 0.6 \\ w_{1} & \text { Spool valve area gradient } 1\left(\mathrm{~m}^{2}\right) & 0.02 \\ w_{2} & \text { Spool valve area gradient } 2\left(\mathrm{~m}^{2}\right) & 0.02 \\ k_{\mathrm{a}} & \text { Servo valve spool position gain }(\mathrm{m} / \mathrm{V}) & 2.54 \times 10^{-4} \\ \omega_{\mathrm{v}} & \text { Servo valve natural frequency }(\mathrm{Hz}) & 506.7 \\ \zeta_{\mathrm{v}} & \text { Servo valve damping ratio } & 0.617 \\ I_{\max } & \text { Max. rate current to servo valve }(\mathrm{A}) & <2 \\ Q_{\max } & \text { Max. permissible flow }(1 / \mathrm{min}) & 80\end{array}$

Leakage parameters

$\begin{array}{ll}x_{0} & \text { Equivalent orifice opening }(\mathrm{m}) \\ k_{\mathrm{f} 1} & \text { Leakage coefficient } \\ k_{\mathrm{f} 2} & \text { Leakage coefficient } \\ K_{\mathrm{f} 1} & \text { Flow gain in port } 1 \\ K_{\mathrm{f} 2} & \text { Flow gain in port } 2\end{array}$

Friction parameters

\begin{tabular}{lll}
$F_{\mathrm{S}}$ & Stiction force $(\mathrm{N})$ & 420 \\
$F_{\mathrm{c}}$ & Coulomb friction $(\mathrm{N})$ & 310 \\
$\sigma_{0}$ & Bristles stiffness coefficient $(\mathrm{N} / \mathrm{m})$ & $14 \times 10^{5}$ \\
$\sigma_{1}$ & Bristles damping coefficient $(\mathrm{N} \mathrm{s} / \mathrm{m})$ & 490 \\
$k_{\mathrm{v}}$ & Viscous friction $(\mathrm{N} \mathrm{s} / \mathrm{m})$ & 110 \\
$v_{\mathrm{s}}$ & Stribeck velocity $(\mathrm{m} / \mathrm{s})$ & 0.02 \\
\hline
\end{tabular}

$1.65 \times 10^{-4}$

0.31
Table 2 Parameters of the controllers

\begin{tabular}{ll}
\hline SMC parameters & \\
$\lambda$ & 3,500 \\
$\eta$ & 10,000 \\
$E$ & $0.25|\hat{a}|$ \\
$b_{\min }$ & $0.75 \times b$ \\
$b_{\max }$ & $1.25 \times b$ \\
$\phi$ & 2.5 \\
$\phi_{a}$ & 2.5 \\
$\phi_{b}$ & 0.5 \\
$\varepsilon_{\mathrm{f}}$ & 0.0005 \\
$\mathrm{PID}$ controller parameters & \\
$K_{\mathrm{p}}$ & 6 \\
$K_{i}$ & 0.15 \\
$K_{\mathrm{d}}$ & 0.0001 \\
\hline
\end{tabular}

troller, fuzzy inferences regulation is used to optimize the PID parameters [25]. A step input signal of $0.02 \mathrm{~m}$ is used to evaluate the sensitivity of the controllers in the presence of friction and internal leakage and to see the effect of varying boundary layers. The $0.02 \mathrm{~m}$ amplitude is a visible value to represent the motion of the piston as compared to the total stroke of the piston, $0.3 \mathrm{~m}$. In both the simulation and experiment, Runge-Kutta solver with a sampling time of $1 \mathrm{~ms}$ is used.

To attain a better tracking performance is the main goal of this work. In evaluating the tracking performance and effectiveness of the proposed controller for the position tracking control, a typical input signal is applied in tracking performance test. This will facilitate to investigate the regulating ability of the controller in point-to-point tracking. The tracking performance is evaluated using sum of squared tracking error (SSTE) and sum of squared control input (SSCI) [30]. The SSTE is used to measure the precision of the tracking while SSCI is employed to observe the control activity in the change of uncertainties and external disturbance. Both performance indexes are given as

$\operatorname{SSTE}=\sum_{t=0}^{N}\left(x_{1 \mathrm{~d}}(t)-\left(x_{1}(t)\right)^{2}\right.$

$\mathrm{SSCI}=\sum_{t=0}^{N} u(t)^{2}$

The simulation and experiment are categorized in four cases. In the first case, sensitivity of SMC, FPID and PID controllers is compared in the presence of friction and internal leakage. The fixed boundary layer is utilized in the SMC. The LuGre friction model is used here. Equivalent orifice opening of the valve is chosen $1.62 \times 10^{-4}$ which is normally used for normal leakage in common valve (no-fault, standard real case) [17]. This level of leakage is used to see 
the effects of internal leakage to the system performance. By maintaining the same friction and internal leakage, the second case involves the comparison of tracking performance of the three controllers. This is followed by the analyses of varying boundary layers that are used to minimize the chattering phenomena in the control signal. Parameters of both boundary layers (fixed and varying) are tabulated in Table 2 . In the last case, control activity and tracking performance of SMC with varying boundary layers are evaluated.

\section{Results and Discussion}

Figures 5 and 6 show the simulation and experimental results for sensitivity performance of SMC, FPID and PID controllers. The obtained results clearly confirm the existence of friction and internal leakage and their effects to the tracking capability of EHA system. Interestingly, previous works
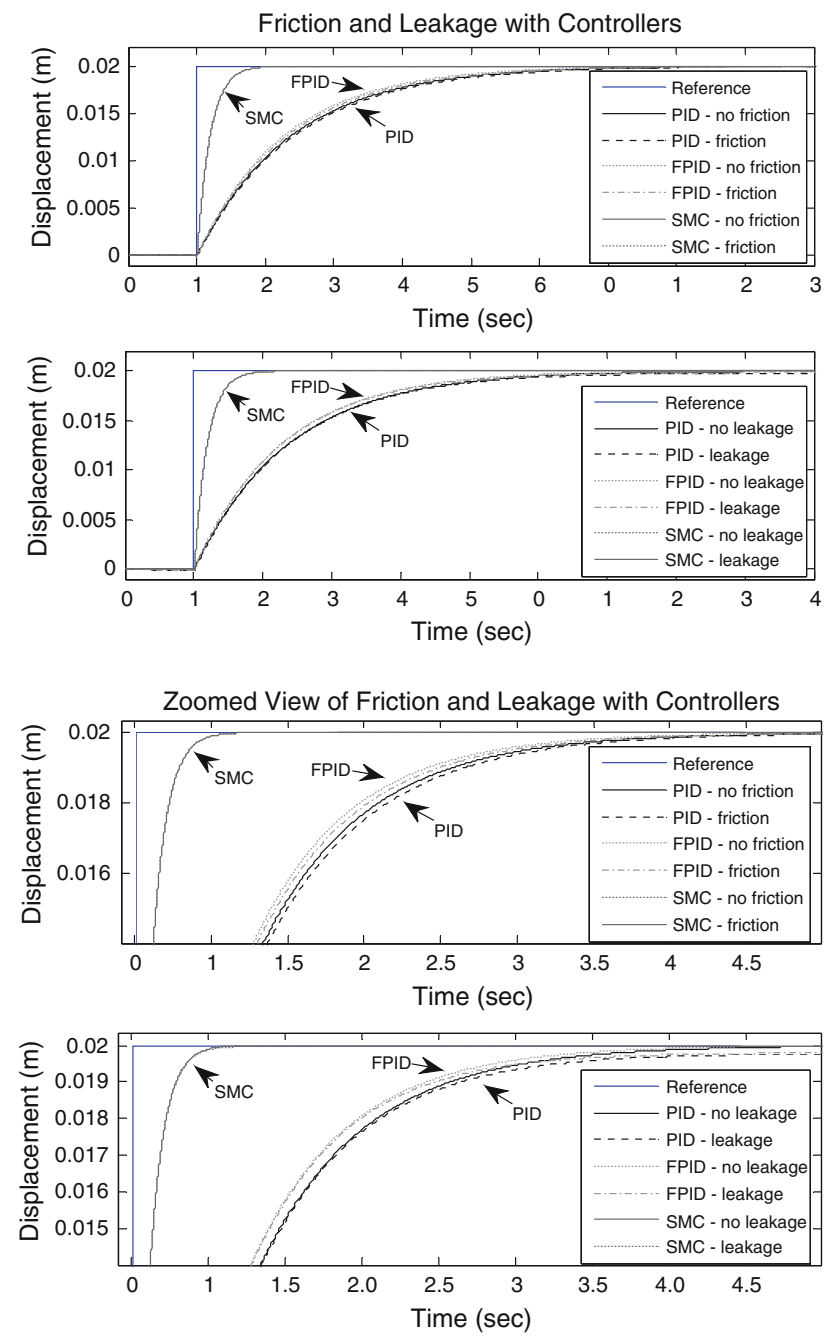

Fig. 5 Controller's sensitivity in the presence of friction and internal leakage (simulation)
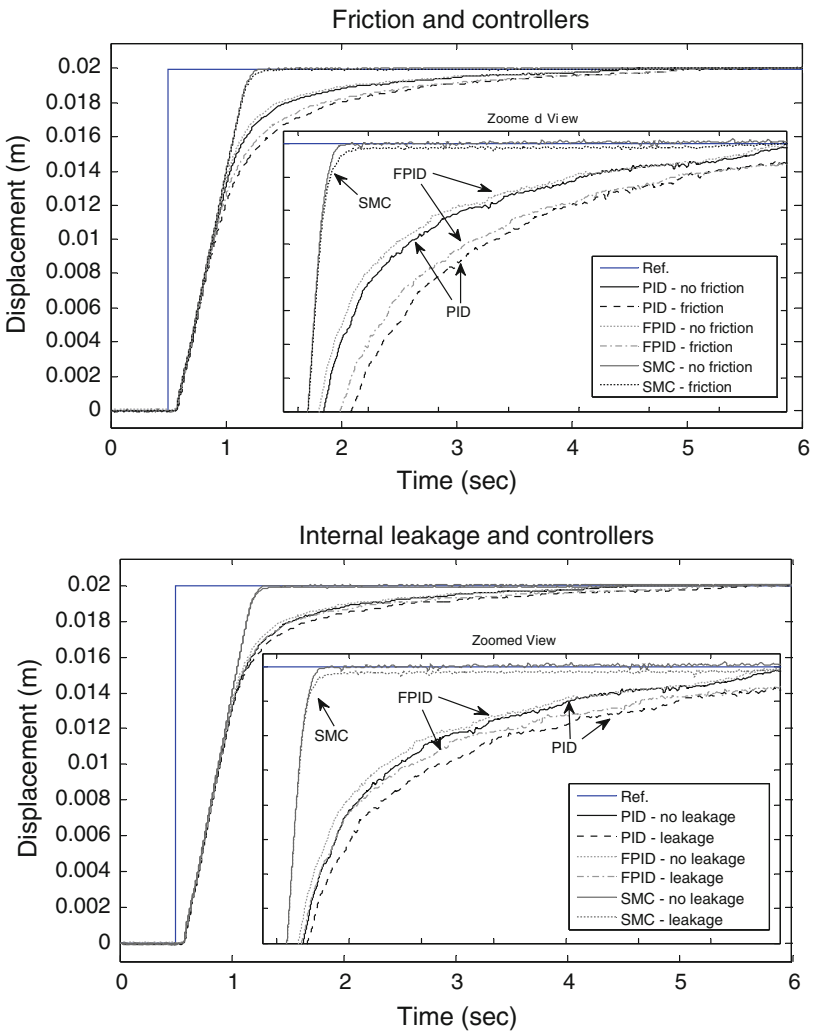

Fig. 6 Controller's sensitivity in the presence of friction and internal leakage (experiment)

have mostly neglected this effect. It can be seen in zoomed view that the contribution of internal leakage is less than friction, reducing the robustness and tracking performance of the system. It is clearly seen that the friction and the internal leakage influence the settling time and steady state error of the displacement response.

It can be noticed that among these three controllers, proposed controller is strongly insensitive to parameter variations and accordingly error trajectory is not changed. This is due to the discontinuous switching gain of the proposed SMC that easily compensates the effects of friction and internal leakage as compared to FPID and PID. This keeps the system states on its sliding surface, even when there are varying uncertainties and external disturbances appearing. However, FPID and PID controllers are not capable enough to resolve this issue. However, the use of fuzzy inference to optimize the PID parameters makes FPID controller slightly more robust over PID controller. These simulation observations have also been supported by experimental verification and are shown in Fig. 6.

In addition to previous test, a point-to-point tracking test is carried out for all three controllers under the presence of internal leakage and friction. The simulation results for this test are shown in Fig. 7, in which position responses, control signals and error trajectories are compared. Once 

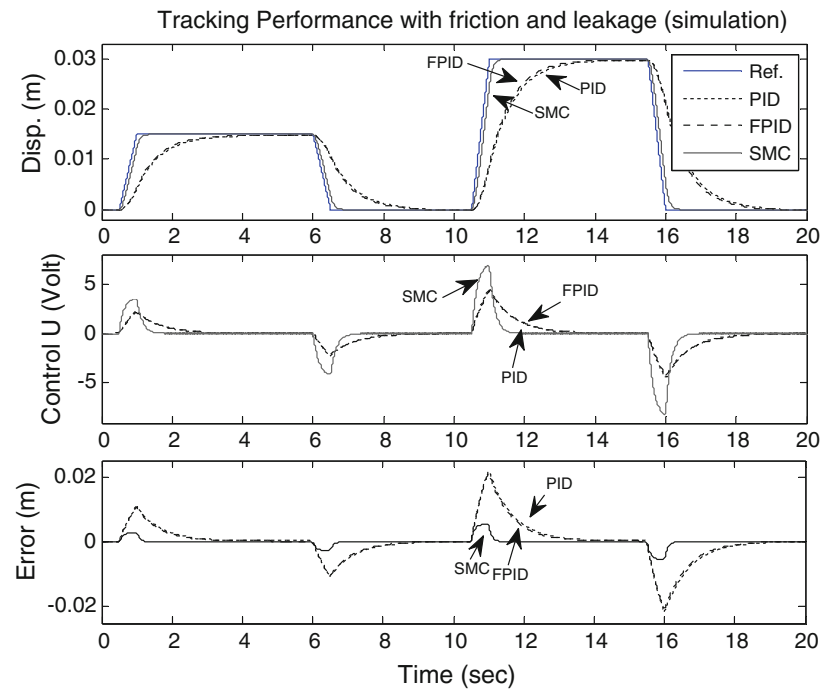

Fig. 7 Tracking performance of the controllers (SMC with fixed boundary layer) (simulation)

Table 3 Tracking performance comparison

\begin{tabular}{lcl}
\hline Controllers & SSTE & SSCI \\
\hline PID, FPID and SMC controllers & \\
Simulation & \\
PID & 0.6438 & $2.5753 \times 10^{4}$ \\
FPID & 0.5844 & $2.6536 \times 10^{4}$ \\
SMC & 0.2980 & $3.3837 \times 10^{4}$ \\
Experiment & & \\
PID & 0.5925 & $9.7507 \times 10^{4}$ \\
FPID & 0.5597 & $9.9790 \times 10^{4}$ \\
SMC & 0.3912 & $1.1872 \times 10^{5}$ \\
SMC with different boundary layers simulation & \\
Fixed & 0.2980 & $3.3837 \times 10^{4}$ \\
Varying & 0.2354 & $4.1753 \times 10^{4}$ \\
Experiment & & $1.1872 \times 10^{5}$ \\
Fixed & 0.3912 & $1.4555 \times 10^{5}$ \\
Varying & 0.3294 &
\end{tabular}

again, the superiority of the SMC in tracking performance is clearly evident over FPID and PID controllers. Its domination is clearly seen in Table 3, which shows a comparison of SSTE and SSCI values for these controllers. SSTE of the SMC has been reduced to 49 and $53 \%$ to that of FPID and PID controllers, respectively. Similarly, SSCI of SMC is also increased to be 27.5 and $31.4 \%$ as compared to both controllers, respectively. Figure 8 shows the experimental results of this test and some important observations are concluded in Table 3. Similar to the simulation results, SSTE of the SMC is found to be decreased by 30.1 and $34 \%$ and SSCI increased by 18.9 and $21.75 \%$ as compared to the FPID and PID controllers, respectively. Again, the better performance

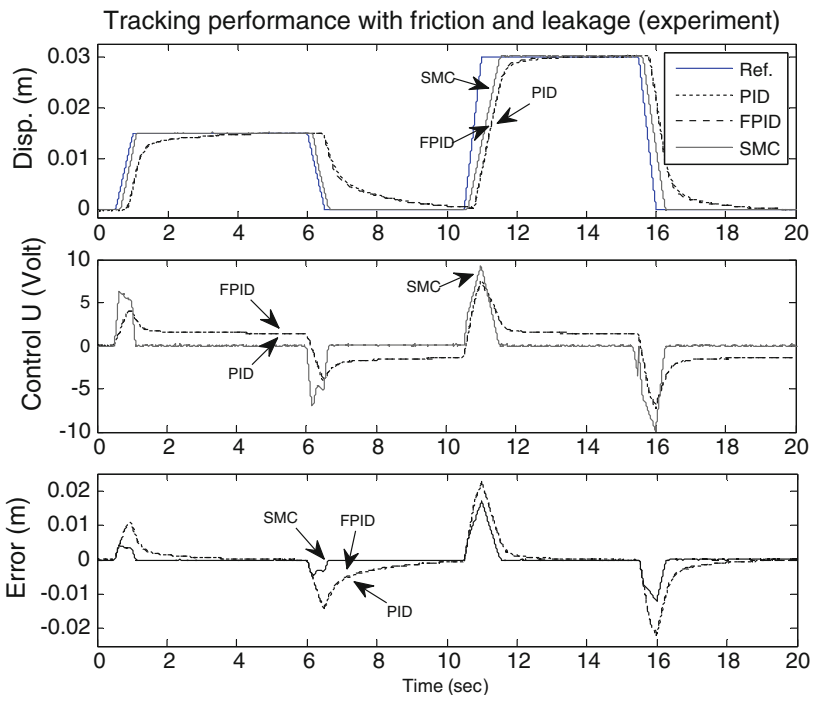

Fig. 8 Tracking performance of the controllers (SMC with fixed boundary layer) (experiment)
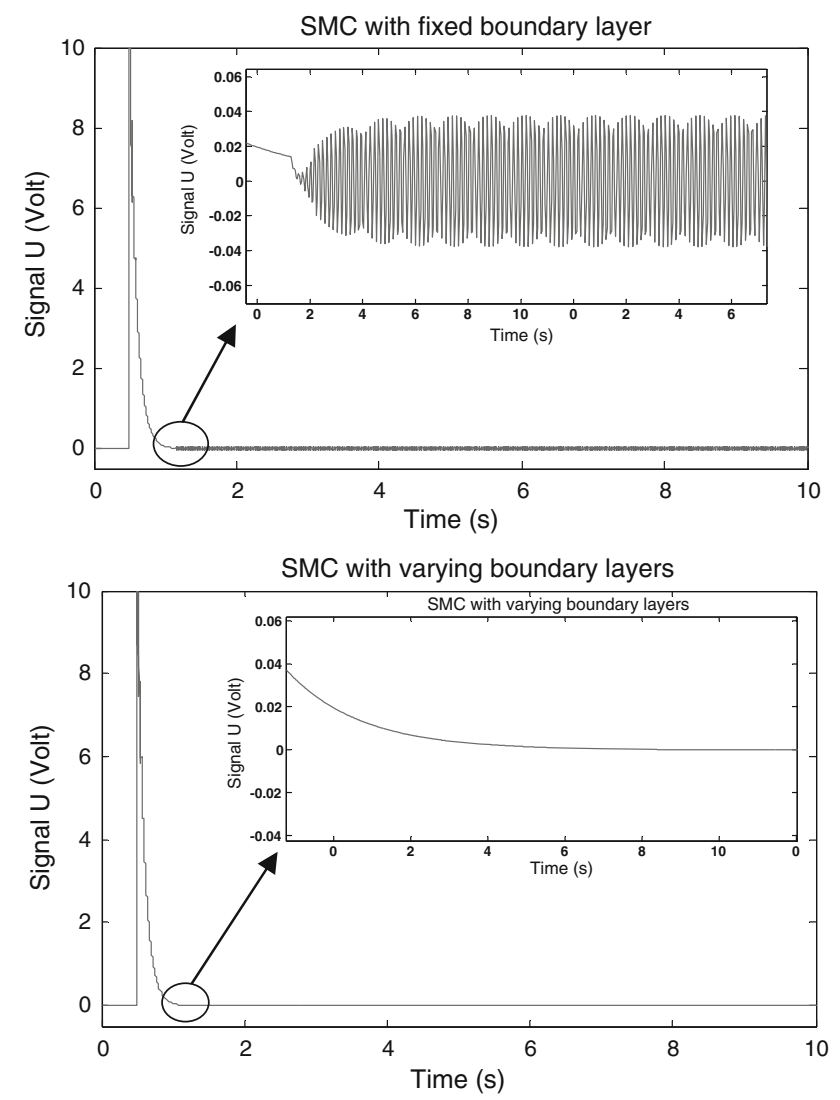

Fig. 9 Control signal of the SMC with fixed and varying boundary layers (simulation)

of proposed SMC is due to the discontinuous switching gain as formulated in (46).

As stated in Sect. 4 that smoother control action is enviable for improved tracking performance. A smooth control 

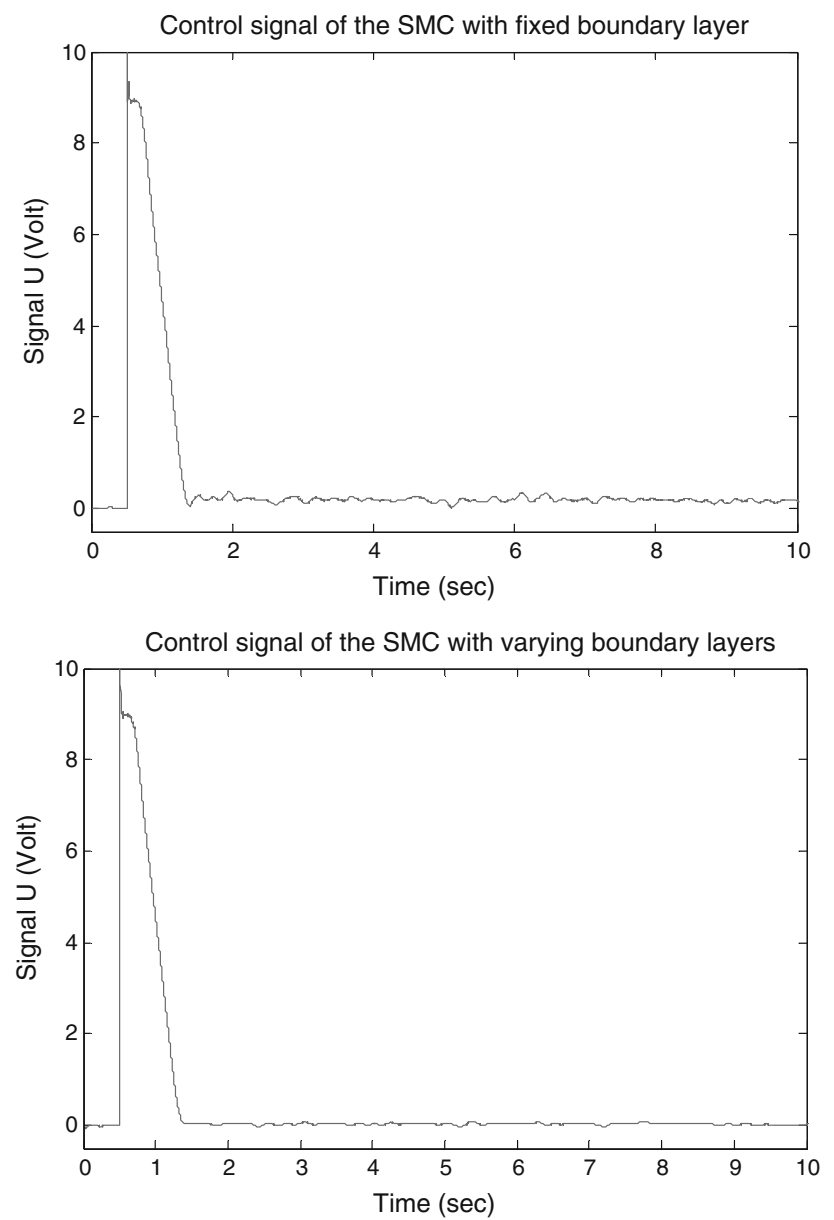

Fig. 10 Control signal of the SMC with fixed and varying boundary layers (experiment)

signal with very small chattering results more accurate tracking results. Hence, the boundary layer is needed to be varying due to the change of error bounds. Figure 9 shows the simulation results of the SMC in relation to the fixed and varying boundary layers. It can be noticed that the control action of SMC having the varying boundary layers has nearly zero chattering behaviour as compared to its counterpart $76 \mathrm{mV}$ peak-to-peak. The experimental results for this comparative study are shown in Fig. 10. It can be seen that there exists a slight deviation of this observation to the simulation results of Fig. 9. This difference could be due to the fact that the amount of uncertainties in simulations and experiment might be different. Furthermore, in this work, the simulation parameters of the SMC are calculated based on the state space model, which is seldom identical to the practical model due to model uncertainties.

Detail observations in point-to-point test on the tracking performance of the SMC in relation to boundary layers issue are carried out in this part. Figure 11 shows the simulation results for the proposed SMC for tracking performance of EHA system. It includes the results of tracking position, con-
Tracking performance of SMC with fixed and varying boundary layers (sim)
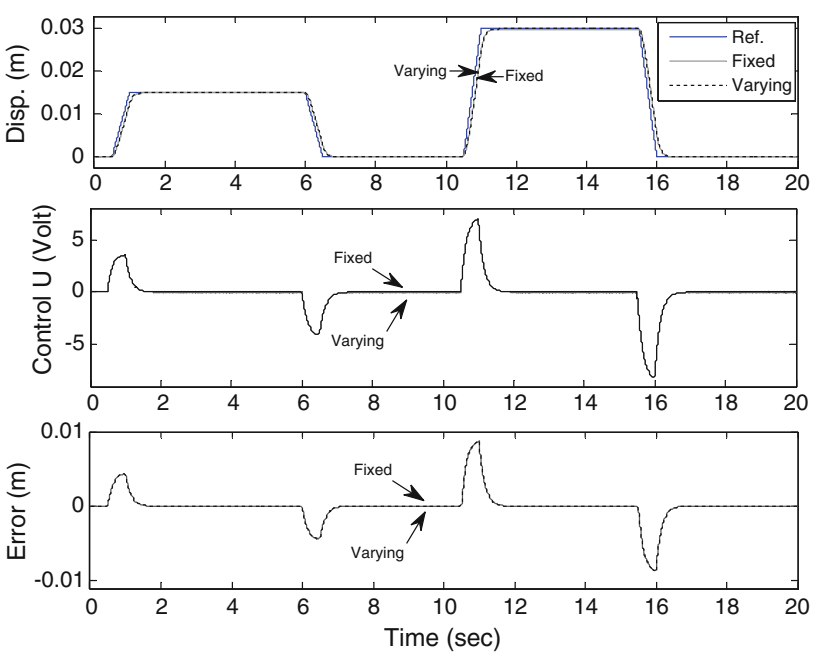

Fig. 11 Tracking performance of the SMC with fixed and varying boundary layers (simulation)
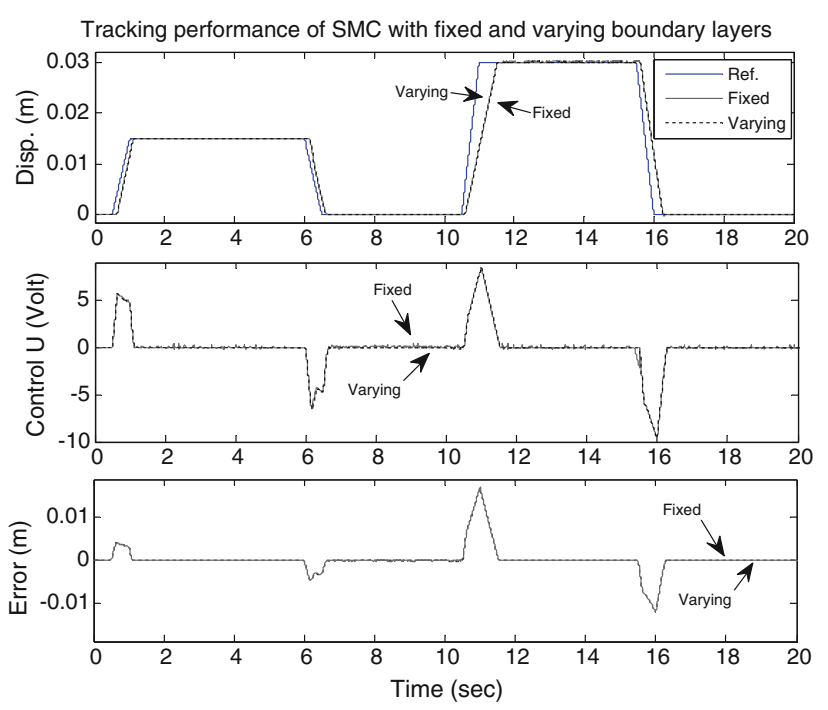

Fig. 12 Tracking performance of the SMC with fixed and varying boundary layers (experiment)

trol signals and error trajectories.In addition, some important observations supported by a comparison of SSTE and SSCI are shown in the last part of Table 3. As expected, the better tracking performance is resulted for the case of varying boundary layers. Compared to the fixed one, its SSTE has been reduced $21 \%$, while its SSCI has been increased around $23.4 \%$. The same trend also has been found in the experimental results as seen in Fig. 12, which has decreased $19.8 \%$ of its SSTE, and increased $22.6 \%$ of its SSCI. This indicates that in the change of tracking error, the varying boundary layers property can improve the tracking performance and the smoothness of the control activity.

Based on the preceding discussions, SMC has been shown to have good capabilities in compensating and handling the 
friction and internal leakage in the EHA system. The use of the varying boundary layer instead of fixed boundary layer property in the SMC scheme has improved the smoothness of the control action. The proposed SMC keeps the system states on its sliding surface even with the existence of varying uncertainties. These improvements guarantee the robustness and tracking performance of the EHA system in positioning. Therefore, implementation of this proposed SMC on EHA systems will offer a significant contribution in positioning applications control of modern equipments.

\section{Conclusion}

The proposed SMC has been successfully employed for accurately tracking the position of on EHA system. Proposed controller adequately compensates the effect of friction and internal leakage. Through point-to-point tracking test, it has the most desirable tracking performance compared to FPID and PID controllers. Augmentation of varying boundary layers in the proposed controller scheme has improved the smoothness of the control action and increased the tracking performance of the system significantly. These simulation works have been verified through experimental studies. The proposed controller offers the promising capabilities to guarantee the robustness and position tracking performance of the system. However, to obtain a smoother control action and better tracking performance, it is envisaged to acquire more accurate estimation of uncertainties.

Acknowledgments This research is supported by Ministry of Science, Technology and Innovation (MOSTI) Malaysia and Universiti Teknologi Malaysia (UTM) through Fundamental Research Grant Scheme (FRGS) number 78591. Authors are grateful to the Ministry and UTM for supporting the present work.

\section{References}

1. Canudas de Wit, C.; Olsson, H.; Astrom, K.J.; Lischinsky, P.: A new model for control of systems with friction. IEEE Trans. Autom. Control. 40(3), 419-425 (1995)

2. Olsson, H.; Astrom, K.J.; Cadunas de Wit, C.; Gafvert, M.; Lischinsky, P.: Friction models and friction compensation. Eur. J. Control. 4(3), 176-195 (1998)

3. Erylmaz, B.; Wilson, B.H.: Combining leakage and orifice flows in a hydraulic servo valve model. ASME J. Dyn. Syst. Meas. Contr. 122, 576-579 (2000)

4. Bobrow, J.E.; Lum, K.: Adaptive high bandwidth control of a hydraulic actuator. ASME J. Dyn. Syst. Meas. Control. 118(4), 714-720 (1996)

5. Plummer, R.; Vaughan, N.D.: Robust adaptive control for hydraulic servo systems. ASME J. Dyn. Syst. Meas. Contr. 118(2), 237-244 (1996)

6. Li, D.; Salcuden, S.E.: Modeling simulation and control of a hydraulic steward platform. In: Proc. of 1997 IEEE Int. Conf. Robot Automation, New Mexico, pp. 3360-3366 (1997)
7. Yun, I.S.; Cho, H.S.: Adaptive model following control of electrohydraulic velocity control system. Proc. Inst. Elect. Eng. 135(2), 149-156 (1998)

8. Tafazoli, S.; De Silva, C.W.; Lawrence, P.D.: Tracking control of an electrohydraulic manipulator in the presence of friction. IEEE Trans. Control Syst. Technol. 6(3), 401-411 (1998)

9. Lischinsky, P.; Canudas de Wit, C.; Morel, G.: Friction compensation for an industrial hydraulic robot. IEEE Control Syst., February, 25-32 (1999)

10. Sekhavat, P.; Wu, Q.; Sepehri, N.: Lyapunov-based friction compensation for accurate positioning of a hydraulic actuator. In: Proceedings of the 2004 American Control Conference, Boston, Massachusetts, USA. June 30-July 2, pp. 418-423 (2004)

11. Iqbal, S.; Bhatti, A.I.: Load varying polytopic based robust controller design in LMI framework for a 2DOF stabilized platform. Arab. J. Sci. Eng. 36(2), 311-327 (2011)

12. Rami, A.M.; Ismail, A.M.; Ibraheem, K.I.: State-space based Hinfinity robust controller design for boiler-turbine system. Arab. J. Sci. Eng. 37(6), 1767-1776 (2012)

13. Bonchis, A.; Corke, P. I.; Rye, D.C.; Ha, Q.P.: Variable structure methods in hydraulic servos systems control. Automatica. 37, 589595 (2001)

14. Mihajlov, M.; Nikolic, V.; Antic, D.: Position control of electro hydraulic servo system using sliding mode control enhanced by Fuzzy PI controller. Facta Universitatis Ser. Mech. Eng. 1(9), 1217$1230(2002)$

15. Wang, S.; Habibi, S.; Burton, R.; Sampson, E.: Sliding mode control for a model of an electrohydraulic system with discontinuous nonlinear friction. In: Proceedings of the 2006 American Control Conference, pp. 418-423, Minneapolis, Minnesota, USA. June 1416 (2006)

16. Zeng, H.; Sepehri, N.: Tracking control of hydraulic actuators using LuGre friction model compensation. ASME J. Dynam. Syst. Meas. Contr. 130, 1-7 (2008)

17. Kalyoncu, M.; Haydim, M.: Mathematical modelling and fuzzy logic based position control of an electrohydraulic servosystem with internal leakage. Mechatronics. 19, 847-858 (2009)

18. Ishaque, K.; Abdullah, S.S.; Ayub, S.; Salam, Z.: Single input fuzzy logic controller for unmanned underwater vehicle. J. Intell. Robot. Syst. 59(1), 87-100 (2010)

19. Ishaque, K.; Abdullah, S.S.; Ayub, S.; Salam, Z.: A simplified approach to design fuzzy logic controller for an underwater vehicle. Ocean Eng. 38(1), 271-284 (2010)

20. Hung, J.Y.; Gao. W.; Hung, J.C.: Variable structure control: a survey. IEEE Trans. Ind. Electron. 40(1), 2-21 (1993)

21. Eker, I.: Second order sliding mode control with PI sliding surface and experimental application to an electromechanical plant. Arab. J. Sci. Eng. 37(7), 1969-1986 (2012)

22. Liu, Y.; Handroos, H.: Technical note sliding mode control for a class of hydraulic position servo. Mechatronics. 9, 111-123 (1999)

23. Guan, C.; Pan, S.: Adaptive sliding mode control of electrohydraulic with nonlinear unknown parameters. Control Eng. Pract. 16, 1275-1284 (2008)

24. Chen, H.-M.; Renn, J.-C.; Su, J.-P.: Sliding mode control with varying boundary layers for an electro-hydraulic position servo system. Int. J Adv. Manuf. Tech. 26, 117-123 (2005)

25. Zulfatman; Rahmat, M.F.: Application of self-tuning Fuzzy PID controller on industrial hydraulic actuator using system identification approach. Int. J. Smart Sens. Intell. Syst. 2(2), 246-261 (2009)

26. Merritt, H.E.: Hydraulic control systems. Wiley, New York (1967)

27. Yao, B.; Bu, F.; Reedy, J.; Chiu, G.T.-C.: Adaptive robust motion control of single-rod hydraulic actuators: theory and experiments. IEEE. ASMI Trans. Mechatron. 5(1), 79-91 (2000)

28. Jerzy, W.; Andrzej, S.; Marian, W.; Thomasz, K.: Hysteretic effects of dry friction: modelling and experimental studies. Phil. Trans. R. Soc. A. 366, 747-765 (2008) 
29. Hang, C.C.; Astrom, K.J.; Ho, W.K.: Refinements of the Ziegler-Nichols tuning formula. IEE Proc.-D. 138(2), 111-118 (1991)
30. Buckner, G.D.: Intelligent bounds on modelling uncertainty: applications to sliding mode control. IEEE Trans. Syst. Man. Cybern. Part C Appl. Rev. 32(2), 113-124 (2002) 